www.jmscr.igmpublication.org

Impact Factor 5.244

Index Copernicus Value: 83.27

ISSN (e)-2347-176x ISSN (p) 2455-0450

crossref DOI: _https://dx.doi.org/10.18535/jmscr/v4i10.107

Journal Of Medical Science And Clinical Research

\title{
Prevalence and Pattern of Sports Injuries among the University Students of Physical Education, Southern India
}

\author{
Authors \\ Indira.N.C ${ }^{1}$, Annie.I.K ${ }^{2}$, A.J.W.Felix ${ }^{3}$ \\ Department of Community Medicine, Rajah Muthaiah Medical College, Annamalai University, \\ Chidambaram, Tamil Nadu, India \\ Corresponding Author \\ N.C.Indira \\ Email: nc.indira.raghavan@gmail.com
}

\begin{abstract}
Background: Sports is a common recreational activity. Besides keeping the physical and mental well being, participation in sports has many advantages like decreasing obesity, cardiovascular disease, hypertension and diabetes mellitus. However, injury risk is considered as an adverse outcome, particularly among physical education trainee students. They have increased chance of getting injuries as their curriculum requires intense training on the techniques and the skills.

Objective: To assess the prevalence and pattern of sports injuries among physical education students of Annamalai University, Tamil nadu, India.

Methodology: Cross sectional study was conducted among the physical education teacher education (PETE) students by using pretested questionnaire. Participants were undergraduate and postgraduate students of the university. Data were analyzed using statistical package for social sciences (SPSS) version 17.

Results: Out of 200 students assessed, 96 had got injured in the preceding six months with the prevalence rate of 48\%. Among the injuries, lower limb (60.3\%) was the commonest region affected. Among the 13 type of sports, volley ball (21.7\%) and kabadi (21.7\%) were the commonest games in which injury occurred. Majority of the injury type observed was contusion (21.1\%) followed by ankle sprain (20.5\%), strain (14.9\%) and ligament tear (14.3\%).

Conclusion: This study shows that almost half of the students of physical education had injury in the preceding 6 months which may affect their training and curriculum participation. There is a need for proper preventive measures to be undertaken to keep the injury risk low among these students.

Keywords: PETE students, sports, injury, knee and ankle.
\end{abstract}

\section{INTRODUCTION}

Sports are one of the commonest recreational activities existing among people for a long time. Although it is an entertainment and has a cultural element, participation in sports have many advantages like decreasing the risk of obesity, cardiovascular disease, hypertension, diabetes mellitus and improving physical fitness. However, sports participation has a risk of injury among players in the professional level to the beginners in sports.

Socio-cultural aspects and health benefits of the sports are known for a long time, but only very little attention is given to the sports related injury. 
Sports injuries are not due to a single factor but variety of factors may interact in causing the injury. The intrinsic or extrinsic factors and the previous injury contribute up to $50-70 \%$ sports injuries, particularly knee and ankle injuries which are common in female, increasing the risk of osteoarthritis in later life ${ }^{(1)}$. Sports injuries can also result from acute trauma or repetitive stress associated with athletic activities and in many cases injuries are due to overuse of a part of the body when participating in certain sports activities (2). Incidence and distribution of sports related injuries vary based on sport affiliation, participation level, player position and gender ${ }^{(3)}$.

Although everyone who participates in sports has the risk of injury, physical education students have higher risk of getting injury because, the university physical education program requires intense training on the techniques and skills. This can expose the physical education teacher education (PETE) students to the increased load on different body parts, making them vulnerable for getting injuries. Recurrence is also more common among the PETE students because of the continuous participation and intense training. Sports injuries, particularly among amateurs account for high rate of morbidity and cost. So, it is important to promote all the preventive measures among young people, stressing on proper technique and creating awareness about the use of protective equipments to decrease the occurrence of sports injuries. It is also important to identify the contributing factors for injury in order to reduce sports injuries.

Sports injuries are a burden for both individual and society. Depending on the nature and severity of the sports injuries, individual lose their working time and quality of life. Permanent damage causing disability and economic burden are all undesired adverse effects of sports injury. Therefore this study was designed with the objective of assessing the prevalence and pattern of sports injuries for the preceding 6 months among PETE students of the University in Tamil Nadu.

\section{MATRIALS AND METHODS}

Cross sectional study was conducted among the college students between the age group 18-30 years from the department of Physical Education, Annamalai University, Chidambaram.

Study was done between November 2015 and August 2016. The second and third year students of physical education trainees were included in the study. Those who were not willing to participate and students not available at the time of administering the questionnaire were excluded from the study. Students in the first year were also excluded as they had joined the college only a month prior to this study.

According to a pilot study conducted the prevalence of sport injuries was $30 \%$. This prevalence was used in calculating sample size of 167. However, sample size was taken as 200 assuming $20 \%$ of the non response.

For the purpose of the study a structured questionnaire was developed. Questionnaire had 2 parts, socio-demographic data and injury details. First part of the questionnaire, was self administered and had details like age, height, weight, course name and year, whether they were injured or not during the preceding 6 months. This was done in 5-7 minutes and researcher was there to see that each and every question was answered. The second part of the questionnaire was about injury details and interviewer administered this to all the participants who had an injury. This contains type of injury, during which sport the injury occurred, and the nature of injury. Data were analyzed by using statistical package for social scinces (SPSS) version 17.

Ethical Issue: Ethical clearance was obtained from the Institutional ethical committee. Permission to carry out the study was sought from the Director of physical education in the University and an informed consent was taken from each participant prior to the study.

Operational definition: Injury is any tissue damage even minor bruises that occurred as a result of training, practice or while playing related to the physical education curriculum. The injury 
may or may not require medical attention and it may or may not affect academic commitment in any form or any length of time.

\section{RESULTS}

Table 1: Demographic characteristics of the study population $(\mathrm{n}=200)$

\begin{tabular}{|l|c|c|c|}
\hline \multirow{4}{*}{ Age } & Variable & No & $\%$ \\
\cline { 2 - 4 } & $18-20$ & 71 & 35.50 \\
\cline { 2 - 4 } & $21-23$ & 78 & 39 \\
\cline { 2 - 4 } & $24-26$ & 38 & 19 \\
\cline { 2 - 4 } Sex & $27-29$ & 13 & 6.50 \\
\hline \multirow{3}{*}{ Course } & Male & 141 & 70.50 \\
\cline { 2 - 4 } & Female & 59 & 29.50 \\
\cline { 2 - 4 } & BPED & 79 & 39.50 \\
\cline { 2 - 4 } & MPED & 19 & 9.50 \\
\hline \multirow{3}{*}{ Year } & BPE & 102 & 51 \\
\cline { 2 - 4 } & Second year & 134 & 67.0 \\
\hline \multirow{2}{*}{ Third year } & 66 & 33.0 \\
\hline
\end{tabular}

Table 1 show that total number of students in the study was 200. Mean age for the study participants was 21.89 years, standard deviation 2.57. Among the study population $70.5 \%$ of them were males and $29.5 \%$ were females. Majority of them $51.0 \%$ were doing BPE course and $67 \%$ of them were pursuing second year of their course.

Table 2: Distribution of study participants according to their height and weight $(n=200)$

\begin{tabular}{|c|c|c|c|c|c|}
\hline \multirow{3}{*}{ Variable } & \multirow{2}{*}{ Measurements } & \multicolumn{2}{|c|}{ Male } & \multicolumn{2}{c|}{ Female } \\
\cline { 2 - 6 } & & No & $\%$ & No & $\%$ \\
\hline \multirow{4}{*}{$\begin{array}{c}\text { Height } \\
\text { (in cms) }\end{array}$} & $141-155$ & 5 & 3.5 & 23 & 39 \\
\cline { 2 - 6 } & $156-170$ & 61 & 43.3 & 30 & 50.8 \\
\cline { 2 - 6 } & $171-185$ & 70 & 49.7 & 5 & 8.5 \\
\hline & $>185$ & 4 & 2.8 & 0 & 0 \\
\hline & $36-50$ & 14 & 9.9 & 41 & 69.5 \\
\cline { 2 - 6 } & $51-65$ & 82 & 58.2 & 17 & 28.8 \\
\cline { 2 - 6 } & $66-80$ & 38 & 26.9 & 1 & 1.7 \\
\cline { 2 - 6 } Weight & $81-95$ & 6 & 4.3 & 0 & 0 \\
\cline { 2 - 6 } (in kgs) & $>95$ & 1 & 0.7 & 0 & 0 \\
\cline { 2 - 6 } & Total & 141 & 100 & 59 & 100 \\
\hline
\end{tabular}

Mean height for males was 170.45, standard deviation 8.14 and mean height for females was 157.85, standard deviation 7.95. Mean weight for males 63.08, standard deviation 9.84, mean weight for females 48.66 and standard deviation 6.23 .
Table 3: Distribution of study participants according to their body mass index

\begin{tabular}{|l|c|c|c|}
\hline \multirow{3}{*}{ Variable } & Measurement & No & $\%$ \\
\hline \multirow{3}{*}{ BMI } & $<18$ & 36 & 18 \\
\cline { 2 - 4 } & $18-24.9$ & 140 & 70 \\
\cline { 2 - 4 }$\left(\mathrm{kg} / \mathrm{m}^{2}\right)$ & $25-30$ & 24 & 12 \\
\cline { 2 - 4 } & $>30$ & 0 & 0 \\
\cline { 2 - 4 } & Total & 200 & 100 \\
\hline
\end{tabular}

Table 3 shows $70 \%$ of the study participants, had normal BMI $\left(18-24.9 \mathrm{~kg} / \mathrm{m}^{2)}\right.$ and $18 \%$ of their BMI was low and $12 \%$ of them were overweight

Table 4: Distribution of participants according to the occurrence of sports injuries

\begin{tabular}{|c|c|c|}
\hline Injured body Part & No of injuries & $\%$ \\
\hline Upper limb & 61 & 37.9 \\
\hline Lower limb & 97 & 60.3 \\
\hline Trunk \& back & 3 & 1.8 \\
\hline Face\& head & 0 & $0 \%$ \\
\hline Total & 161 & $100 \%$ \\
\hline
\end{tabular}

Table 4 shows the prevalence of sports injury was 48\%. Among the 200 study population 96 students got injured during the past 6 months

Table 5: Distribution of injuries according to the sports involved in sports injuries (No of total injuries occurred in the past 6 months $=161$ )

\begin{tabular}{|c|c|c|}
\hline Sports & No of injuries & $\%$ \\
\hline Foot ball & 23 & 14.3 \\
\hline Volley ball & 35 & 21.7 \\
\hline Athletic & 9 & 5.6 \\
\hline Kabadi & 35 & 21.7 \\
\hline Tennis & 3 & 1.9 \\
\hline Basket ball & 17 & 10.6 \\
\hline Khokho & 11 & 6.8 \\
\hline Badminton & 6 & 3.7 \\
\hline Cricket & 11 & 6.8 \\
\hline Karate & 1 & 0.6 \\
\hline Weight lifting & 2 & 1.2 \\
\hline Hockey & 5 & 3.1 \\
\hline Gymnastics & 3 & 1.9 \\
\hline Total & 161 & 100 \\
\hline
\end{tabular}

Among the total 161 injuries occurred during the preceding 6 months, majority $21.7 \%$ of the 
injuries occurred in volley ball and $21.7 \%$ of injuries occurred in kabadi. Next common sport injuries occurred was football (14.3\%). Karate was the game in which least number injuries $(0.6 \%)$ occurred.

Table 6: Distribution of injuries according to body region affected

\begin{tabular}{|l|l|l|}
\hline Variable & No & $\%$ \\
\hline Injured & 96 & 48.0 \\
\hline Non injured & 104 & 52.0 \\
\hline Total & 200 & 100 \\
\hline
\end{tabular}

Table 6 shows majority of the injuries occurred in the lower limb $(60.3 \%)$, followed by upper limb with $37.9 \%$ of the injuries.

Table7: Distribution of injuries according to the types of injury

\begin{tabular}{|l|l|l|}
\hline Injury types & No & $\%$ \\
\hline Fracture & 5 & 3.1 \\
\hline Dislocation & 13 & 8.1 \\
\hline Ligament tear & 23 & 14.3 \\
\hline Laceration & 4 & 2.5 \\
\hline Abrasion & 7 & 4.3 \\
\hline Contusion & 34 & 21.1 \\
\hline Concussion & 0 & 0 \\
\hline Strain & 24 & 14.9 \\
\hline Ankle sprain & 33 & 20.5 \\
\hline Tennis elbow & 0 & 0 \\
\hline Runner's knee & 6 & 3.7 \\
\hline Shoulder impingement & 12 & 7.5 \\
\hline Total & 161 & 100 \\
\hline
\end{tabular}

Table 7 shows that the commonest injury was contusion $21.1 \%$ followed by ankle sprain $20.5 \%$, strain $14.9 \%$ and ligament tear $14.3 \%$. Tennis elbow and concussion occurrence were nil.

\section{RESULTS}

Study participants comprised of males (141, $70.5 \%)$ and females $(59,29.5 \%)$ totally 200. Mean age was 21.89 years with the standard deviation 2.57. Majority $(134,67 \%)$ were pursuing their $2^{\text {nd }}$ year of their course. Mean height for males was 170.45 , standard deviation 8.14 and for females mean height were 157.85, standard deviation 7.95. Mean weight for males was 63.08, standard deviation 9.84 and for females it was 48.66, standard deviation 6.23. Regarding their body mass index, (140, 70\%) were having normal $\left(18-24.9 \mathrm{~kg} / \mathrm{m}^{2}\right)$ BMI.

\section{Prevalence and pattern of sports injuries}

The study accounts for the overall prevalence of sports injuries in the past 6 months as $48 \%$ (96 injured among 200 students). Total of 161 injuries occurred in the preceding 6 months. Regarding the nature of injuries, $55.3 \%$ of the injuries were new injuries and $44.7 \%$ of them were recurrent injuries.

Injury occurrence was highest among players of volley ball $(21.7 \%)$ and kabadi $(21.7 \%)$ and it was least in karate $(0.6 \%)$. Other sports in which injury acquired were foot ball $14.3 \%$, basket ball $10.6 \%$, khokho and cricket $6.8 \%$ each, athletic $5.6 \%$, badminton $3.7 \%$, hockey $3.1 \%$, tennis $1.9 \%$, gymnastics $1.9 \%$ and weight lifting $1.2 \%$.

This study shows that lower limb was the most commonly affected body region $60.3 \%$ followed by the upper limb $37.9 \%$, trunk and back $1.8 \%$ and no injury occurred on face and head.

According to the type of injury, most common injury was contusion $21.1 \%$ followed by ankle sprain $20.5 \%$. Other injuries were strain $14.9 \%$ and ligament tear $14.3 \%$, dislocation $8.1 \%$, shoulder impingement $7.5 \%$, abrasion $4.3 \%$, runner's knee $3.7 \%$ fracture 3.1 , laceration $2.5 \%$ Concussion and tennis elbow occurrence were nil.

\section{DISCUSSION}

The University PETE students have a rigorous training in various sports during their course making them more susceptible to sports injuries . Total of 200 PETE students were included in this study and majority of them were in the age group of $21-23$ years, $70.5 \%$ of them were males and $29.5 \%$ of them were females. This was in concordance with other studies ${ }^{(4,5)}$ in which male participation was higher than female participation. This study result shows that overall 161 injuries occurred and $48 \%$ of the students got injured in the preceding 6 months. Similar results had been obtained about the prevalence of injuries by Bruno 
Berbertrosa et al ${ }^{(6)}$ among collegiate athletes which was $49.9 \%$ and another study done by Stevenson et al ${ }^{(7)}$. But the result was inconsistent with study done by Ying zhao et al ${ }^{(8)}$ among college students in Wuhan city in which prevalence was low (15.59\%). The difference might be due to the injury definition in this study and the injuries were more inclusive and irrespective of medical attention and time loss. Similar prevalence was present in the study done by Swarup Mukherjee ${ }^{(9)}$ among PETE students, which suggests that the University PETE students are at higher risk of getting sports injuries compared to general active sports population.

The lower limb was the most commonly affected body part accounting $60.3 \%$ of the injuries in this study. This was in concordance with the previous studies done among PETE students (9,10,11,12) suggesting that the lower limb has increased risk of getting injuries among the PETE students. Similar findings were seen in studies ${ }^{(13,14)}$ where lower extremities were the most affected part. This might be explained by the high intensity intermittent and impact loading nature of sports like hockey, basket ball, and foot ball in the curriculum. It seems that the reasons of low frequency of injuries in head and neck may be due to increased range of motion of upper limb and lower limb compared to low amplitude movements in the head and neck regions in many sports.

In this study Contusion (21.1\%) was the commonest type of injury sustained during the physical education curriculum followed by ankle sprain $20.5 \%$, strain $14.9 \%$, ligament tear $14.3 \%$. Similar findings obtained by Jui Ray et al (10) among physical education college students, the commonest injuries were contusion $41 \%$, sprains 22\%. However, Swarup Mukerjee et al, in his study has noted $31 \% \%$ sprain was the commonest type of injury, followed by contusion $20 \%$, muscle strain $14 \% .{ }^{(9)}$. This findings were on the contrary to the studies ${ }^{(8,15)}$ done among in which skin damage $38.95 \%$ and ligament sprain $43 \%$ were the commonest injuries.
Among the 13 types of sports activities in our study, the commonest sports involved in sports injuries were volley ball $21.7 \%$ and kabadi $21.7 \%$ These findings were in contrary to the study done at ${ }^{(16)}$ in which foot ball, field hockey were the commonest sports involved with sports injuries occurred in lower limb done by Varun Kumar et al shows in which basket ball and cricket were the common sports involved with sports injuries. More injuries occurred in volley ball in this study. This may be due to inadequate practice and incorrect technical movements whereas in kabadi collision injuries were more common.

\section{CONCLUSION}

Prevalence of sports injuries in physical education students in our study was found to be $48 \%$. The results showed that the PETE students were at a high risk of sports injuries. There was a total of 161 injuries for the past 6 months in which lower limb was the overall most commonly affected body part and the upper limb accounted for a significant number of curriculum related injuries. Contusion was the commonest injury type, but ankle sprain and ligament tear were also common injuries that increases the risk of recurrent injuries among the PETE students. The volleyball and kabadi were the commonest sports in which injuries were more.

\section{LIMITATIONS}

The generalization of the study result is limited by the characteristic of the sample which was recruited from the single college. Recall bias is inevitable for minor sports injuries because the study was done retrospectively. The limitations and reliability of retrospective sports injury studies need to be taken into account in drawing conclusions from the survey.

\section{RECOMMENDATIONS}

Knowledge about sports injuries is useful to identify the proper training programs to prevent injuries. Physical exercise and sports activities must be appropriate for the physical characteris- 
tics of the students. Physical education teachers should continuously be aware of the potential dangers for sports injuries and about the practical measures to reduce risk of injuries.

\section{RFERENCES}

1. Conn JM,Annest JL Gilchrist J. Sports and recreation related injury episodes in US population1997-1999. Inj prevention. 2003 ;9:117-123

2. HergenroederAC.Prevention of sports injuries.Paediatrics1998;101:1057-1063

3. ShanmugamC,MafulliN.Sports injuries in children. Br Med Bull . 2008;86:33-57

4. Knowles SB, Marshall SW, Bowling JM, Loomis D, Milikan R, et. al. A prospective study of injury incidence among North Carolina high school athletes. Am J Epidemiol. 2006; 164: 1209-1221.

5. Ingram JG, Fields SK, Yard EE, Comstock RD. Epidemiology of knee injuries among boys and girls in US high school athletics. Am J Sports Med. 2008; 36: 1116-1122.

6. Bruno Berbert Rosa and et. al. Epidemiology of sports injuries on collegiate athletes at a single center. ActaortopediaBrasilaira. 22(6).

7. Stevenson MR, Hamer P, Finch CF, Elliot B, Kresnow M. Sports, age, and sex specific incidence of sports injuries in Western Australia. Br J Sports Med. 2000; 34: 188-194

8. Ying Zhao. Study on Sports Injuries among College Students in Wuhan. Advances in Physical Education. 2013; 3(2):89-91.

9. Swarup Mukherjee. Sports Injuries in University Physical Education Teacher Education Students: A Prospective Epidemiological Investigation. JJ Sports Med. 2014; 1(2):006.

10. M.K.Jui Ray and M.Kohandel. Epidemiology of some sports injuries among physical education college stud-ents.
Injury Prevention. 2010; 16(1):A128A129.

11. Flicinski. J. Occurrence and risk factors of musculoskeletal pain and sport injuries in students of physical education in University of Szczecin. Ann Acad Med Stetin. 2008; 54(3): 31-47.

12. Goosens L, Verrelst R, Cardon G, De Clercq D. Sports injuries in physical education teacher education students. Scand J Med Sci Sports. 2013.

13. Cromwell F, Walsh J, Gormley J. A pilot study examining injuries in elite gaelic footballers. Br J Sports Med. 2000; 34: 104-108.

14. Van Gent RN, Siem D, van Middelikoop $M$, van Os AG, Biema-Zeinstra SM. et. al. Incidence and determinants of lower extremity running injuries in long distance runners: a systematic review. Br J Sports Med. 2007; 41: 469-480.

15. Dustin Nabhan, Taylor Walden, Jenna Street, Heather Linden, Bill Moreau. Sports injury and illness epidemiology during the 2014 Youth Olympic Games: United States Olympic Team Surveillance. Br.J. Sports Medicine. 2016; 0:1-6.

16. Faude O, Robler R, Junge A. Football injuries in children and adolescent players: are there clues for prevention?. Sports Med. 2013. 43: 819-837. 31 Bruno

Berbert Rosa and et. al. Epidemiology of sports injuries on collegiate athletes at a single center. Actaortopedia Brasilaira. 22(6).

17. Varun Kumar, AbhaMangal, GeetaYadav, Deepak K. Raut, Saudan Singh. Prevalence and pattern of sports injuries among college students in Delhi, India. Saudi Journal of sports medicine. 2014;14(2):109-113. 